cytotoxic T cells) returned to normal levels. ${ }^{2}$ In the two patients described by Clatworthy et al., the number of CD8+ T lymphocytes was low (190 and 80 cells per cubic millimeter; normal range, 200 to 900), but the number of CD19+ cells was within the normal range. Since alemtuzumab could eliminate about $77 \%$ of $\mathrm{CD} 8+\mathrm{T}$ lymphocytes by means of non-complement-mediated mechanisms, ${ }^{3}$ persistently suppressed CD8+ T cells could have influenced the development of anti-glomerular basement membrane antibodies in their patients.

Jae II Shin, M.D.

Jae Seung Lee, M.D.

Yonsei University College of Medicine

Seoul 120-752, Korea

pedshin2000@yahoo.co.kr

1. Clatworthy MR, Wallin EF, Jayne DR. Anti-glomerular basement membrane disease after alemtuzumab. N Engl J Med 2008; 359:768-9.

2. Ligler FS, Westby GR, Hertz BC, Durning CM, Cohen R, Bonner H. Immunoregulatory cell subsets in Goodpasture's syndrome: evidence for selective T suppressor-cell depletion during active autoimmune disease. J Clin Immunol 1983;3:368-74.

3. Lowenstein H, Shah A, Chant A, Khan A. Different mechanisms of Campath-1H-mediated depletion for CD4 and CD8 T cells in peripheral blood. Transpl Int 2006;19:927-36.

THE AUTHORS REPLY: Shin and Lee suggest that the development of anti-glomerular basement membrane disease in two patients treated with alemtuzumab was due to a deficiency of CD8 suppressor $\mathrm{T}$ cells. The speculation is based on a description of a patient with atypical, spontaneously resolving, anti-glomerular basement membrane disease in which low levels of so-called CD8 suppressor T cells were observed. ${ }^{1}$ The OKT8 antibody that was used to define suppressors in this article merely identifies CD8 $\mathrm{T}$ cells, with no demonstra- tion of a deficiency of suppressor function within this subgroup. Aside from the limitations of this article, CD8 T-cell depletion actually prevents or ameliorates disease in animal models of anti-glomerular basement membrane disease. ${ }^{2}$ In addition, data suggest that $\mathrm{CD} 8$ regulatory $\mathrm{T}$ cells in humans reside in the $\mathrm{CD} 8+\mathrm{CD} 28-$ T-cell compartment. $^{3}$ After treatment with alemtuzumab, this regulatorcontaining $\mathrm{CD} 8+\mathrm{CD} 28$ - subgroup is enriched within the reconstituted CD8 T-cell compartment. ${ }^{4}$

Since acceptance of our letter, we have become aware that one of our two patients was previously mentioned in the adverse-effects section of an article on alemtuzumab in multiple sclerosis. ${ }^{5}$

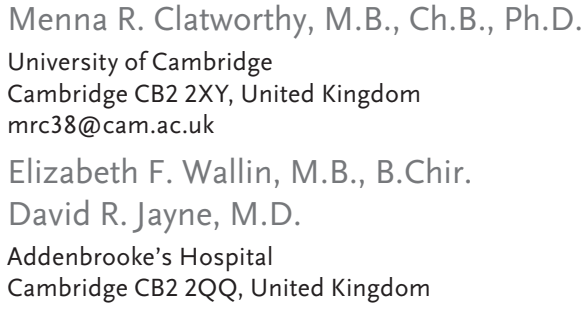

1. Ligler FS, Westby GR, Hertz BC, Durning CM, Cohen R, Bonner H. Immunoregulatory cell subsets in Goodpasture's syndrome: evidence for selective T suppressor-cell depletion during active autoimmune disease. J Clin Immunol 1983;3:368-74.

2. Reynolds J, Norgan VA, Bhambra U, Smith J, Cook HT, Pusey CD. Anti-CD8 monoclonal antibody is effective in the prevention and treatment of experimental autoimmune glomerulonephritis. J Am Soc Nephrol 2002;13:359-69.

3. Chang CC, Ciubotariu R, Manavalan JS, et al. Tolerization of dendritic cells by $\mathrm{T}(\mathrm{S})$ cells: the crucial role of inhibitory receptors ILT3 and ILT4. Nat Immunol 2002;3:237-43.

4. Trzonkowski P, Zilvetti M, Chapman S, et al. Homeostatic repopulation by CD28-CD8+ $\mathrm{T}$ cells in alemtuzumab-depleted kidney transplant recipients treated with reduced immunosuppression. Am J Transplant 2008;8:338-47.

5. Coles AJ, Cox A, Le Page E, et al. The window of therapeutic opportunity in multiple sclerosis: evidence from monoclonal antibody therapy. J Neurol 2006;253:98-108.

\title{
Osteosarcoma Derived from Donor Stem Cells Carrying the Norrie's Disease Gene
}

TO THE EDITOR: There have been few reports of osteosarcoma after allogeneic bone marrow transplantation. ${ }^{1}$ We report the development of osteosarcoma in a recipient 17 years after stem-cell transplantation.

A 23-month-old boy with $\beta$-thalassemia received a bone marrow transplant from his HLAidentical 11-year-old brother in September 1989.
Norrie's disease had been diagnosed in the donor at 12 months of age, after enucleation of the right eye was performed because a bilateral retinoblastoma was suspected. No genetic analysis was conducted at the time of surgery. Norrie's disease is an X-linked recessive disease caused by mutations in the NDP gene on Xp11.4. ${ }^{2}$ It primarily affects the eye and almost always leads to blind- 


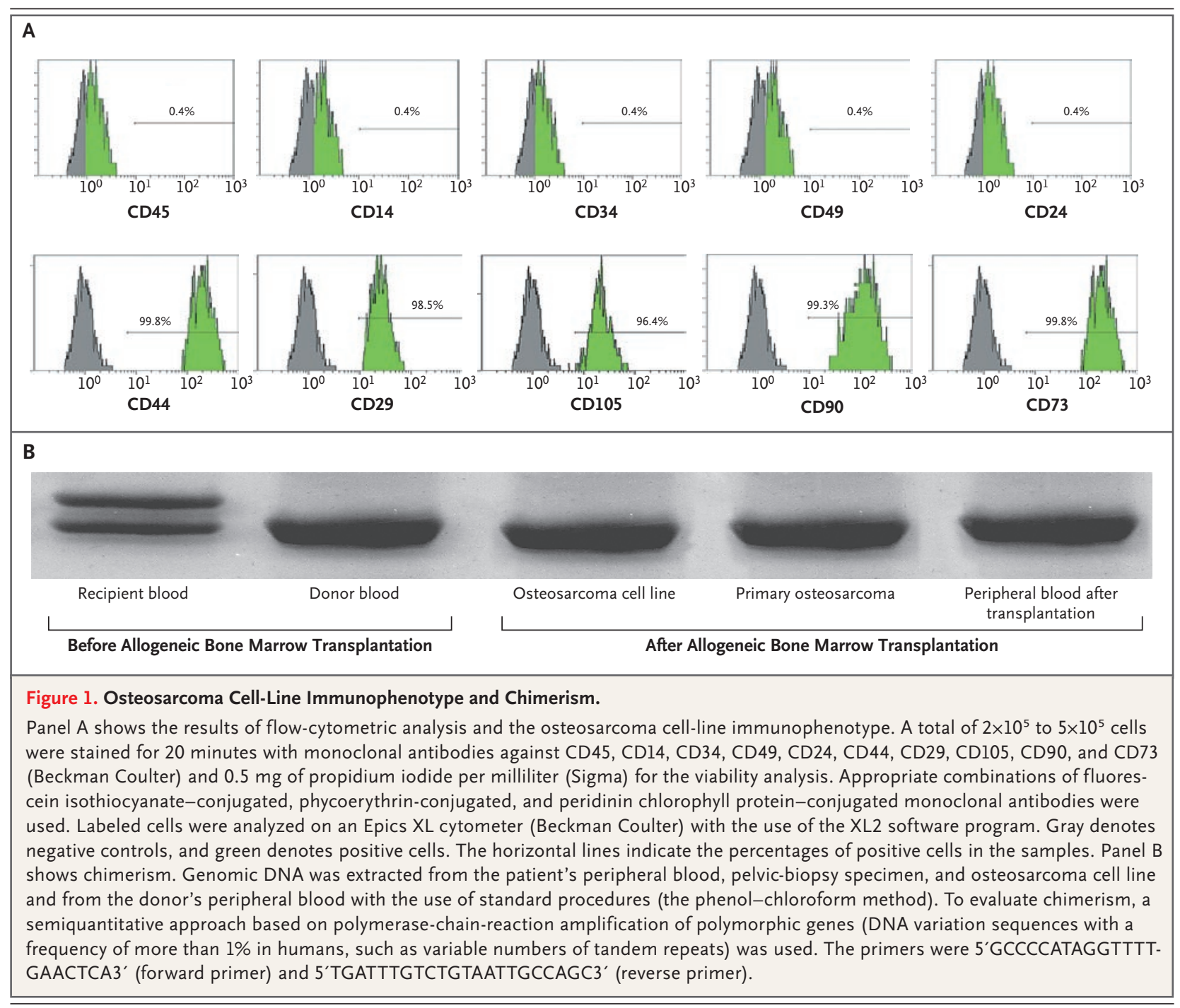

ness. The chemotherapy regimen before the bone marrow transplantation consisted of high-dose cyclophosphamide and busulfan. From day 30, the recipient was a complete hematopoietic chimera. Seventeen years later, a metastatic chondroblastic osteosarcoma of the pelvis developed in the 18-year-old recipient. Despite aggressive treatment, the patient died of tumor progression 22 months after the diagnosis of osteosarcoma and 19 years after stem-cell transplantation.

An osteosarcoma cell line that was established from the recipient's tumor had a doubling time of 168 hours ( 7 days) (the normal doubling time in a generated osteosarcoma cell line is 1.4 to 37.0 days). The cells expressed mesenchymal stem-cell markers (CD44, CD29, CD105, CD90, and CD73) at a very high level (Fig. 1), but they did not express CD45, CD14, CD34, CD49, or CD24. Cells from the osteosarcoma cell line were examined by means of cytogenetic analysis and fluorescence in situ hybridization (FISH) with the use of a specific probe for the $p 53$ gene. ${ }^{3}$ Fifty metaphases were analyzed after GTG banding. Two distinct karyotypes were found: $47 \mathrm{XY},-5,+22,+\mathrm{m}$ and $45 \mathrm{XY},-12,-15,+\mathrm{m}$. Blood samples from the recipient and donor had wild-type copies of chromosome 17, whereas the osteosarcoma cell line showed trisomy 17 in 22 of 100 interphase nuclei. Neither the cytogenetic analysis nor p53 FISH analysis of the primary tumor was performed because of an inadequate specimen, and for ethical reasons, donor mesenchymal stem cells were not 
analyzed at the time of the diagnosis of osteosarcoma. A semiquantitative method based on polymerase-chain-reaction amplification of polymorphic genes showed complete donor chimerism of recipient hematopoietic cells, the cells from the osteosarcoma-biopsy specimen, and the osteosarcoma cell line (Fig. 1). ${ }^{3}$ Moreover, the blood samples from the donor and the recipient, the osteosarcoma-biopsy specimen, and the osteosarcoma cell line had a mutation of L15R of exon 2 of the NDP gene, whereas swab cells from the recipient's oral cavity did not.

Our data suggest the donor origin of the osteosarcoma. The mutated NDP in the osteosarcoma cells was most likely a marker of chimerism, because cancer did not develop in the donor, and Norrie's disease is not associated with an increased risk of cancer.

\author{
Massimo Berger, M.D. \\ Michela Muraro, M.D. \\ Franca Fagioli, M.D. \\ Ospedale Infantile Regina Margherita \\ 10126 Turin, Italy \\ massimo.berger@unito.it
}

\section{Stefano Ferrari, M.D.}

Istituto Ortopedico Rizzoli

40136 Bologna, Italy

1. Bielack SS, Rerin JS, Dickerhoff R, et al. Osteosarcoma after allogeneic bone marrow transplantation: a report of four cases from the Cooperative Osteosarcoma Study Group (COSS). Bone Marrow Transplant 2003;31:353-9.

2. Rosenberg T. Epidemiology of hereditary ocular disorders. Dev Ophthalmol 2003;37:16-33.

3. Gokgoz N, Wunder JS, Mousses S, Eskandarian S, Bell RS, Andrulis IL. Comparison of p53 mutations in patients with localized osteosarcoma and metastatic osteosarcoma. Cancer 2001;92: 2181-9.

Correspondence Copyright (c) 2008 Massachusetts Medical Society.

INSTRUCTIONS FOR LETTERS TO THE EDITOR

Letters to the Editor are considered for publication, subject to editing and abridgment, provided they do not contain material that has been submitted or published elsewhere. Please note the following: $\cdot$ Letters in reference to a Journal article must not exceed 175 words (excluding references) and must be received within 3 weeks after publication of the article. Letters not related to a Journal article must not exceed 400 words. All letters must be submitted over the Internet at http://authors.nejm.org. -A letter can have no more than five references and one figure or table. • A letter can be signed by no more than three authors. - Financial associations or other possible conflicts of interest must be disclosed. (Such disclosures will be published with the letters. For authors of Journal articles who are responding to letters, this information appears in the published articles.) -Include your full mailing address, telephone number, fax number, and e-mail address with your letter.

Our Web site: http://authors.nejm.org

We cannot acknowledge receipt of your letter, but we will notify you when we have made a decision about publication. Letters that do not adhere to these instructions will not be considered. Rejected letters and figures will not be returned. We are unable to provide prepublication proofs. Submission of a letter constitutes permission for the Massachusetts Medical Society, its licensees, and its assignees to use it in the Journal's various print and electronic publications and in collections, revisions, and any other form or medium. 